\title{
The modelling and simulation of IoT system in healthcare applications
}

\author{
Nurul Amirah Mashudi ${ }^{1}$, Hazilah Mad Kaidi ${ }^{2}$, Shamsul Sarip ${ }^{3}$ and Liza Abdul Latiff ${ }^{3}$ \\ Scholar, Software Development and Multimedia Services Centre, Universiti Tunku Abdul Rahman, Malaysia ${ }^{1}$ \\ Senior Lecturer, Razak Faculty of Technology and Informatics, Universiti Teknologi Malaysia, Malaysia ${ }^{2}$ \\ Associate Professor, Razak Faculty of Technology and Informatics, Universiti Teknologi Malaysia, Malaysia ${ }^{3}$
}

Received: 1-November-2020; Revised: 25-January-2021; Accepted: 26-January-2021

(C)2021 Nurul Amirah Mashudi et al. This is an open access article distributed under the Creative Commons Attribution (CC BY) License, which permits unrestricted use, distribution, and reproduction in any medium, provided the original work is properly cited.

\begin{abstract}
This paper presents a review on modelling and simulation of Internet of things (IoT) in healthcare application. IoT is a large-scale ecosystem of socio-technical application. The emerging technology of IoT has gained enormous attention in a wide range of industries and used in various kind of environments. Healthcare application is one of the vital IoT applications for smart cities. Medical devices and applications of IoT healthcare are emerging rapidly in the global market. Various IoT-based health applications have been proposed to help patients monitor the disease and track the health information without visiting the hospital, clinic, or any medical centre. This paper has briefly described the methods and devices used in IoT-based healthcare application, namely blood pressure monitoring, glucose and cholesterol monitoring, asthma monitoring, and stroke rehabilitation system. The modelling and simulation process of IoT-based healthcare applications are discussed on blood pressure and stroke rehabilitation system only. The development of electrocardiogram (ECG) and Photoplethysmogram (PPG) in blood pressure measurement integration with a smartphone has created simplicity and usability of the device. Nevertheless, further investigation is required to improve the accuracy in collecting the patient's health information. For hand rehabilitation training purposes, an IoTenabled stroke rehabilitation device depends on machine learning, smart wearable armband and a $3 D$ printed robot hand were developed to imitate the movements of the patient in a real-time mode. The feature selection used in the development of the device using machine learning has produced a high classification accuracy which helps stroke patients to strengthen the muscles with their motion patterns after stroke.
\end{abstract}

\section{Keywords}

Internet of things, Healthcare application, Modelling and simulation.

\section{Introduction}

A megatrend towards the future and advancement of IoT technologies is emerging rapidly as more and more integrated devices and sensors are being envisioned. IoT receives and transmits fine-grained data that contain multimedia contents such as photo, video, and audio, with a growing number of devices. According to Cisco and Ericsson Incorporation, the Internet would be accessible by 50 billion devices in $2020[1,2]$, and the figure will exceed 500 billion devices by 2025 [3]. The IoT is a huge network that allows connecting devices in the cloud to capture and exchange data namely smartphones, PDAs, smart meters, RFID tags, smart cars, smart sensors, Machine-to-Machine (M2M) and other embedded devices $[4,5]$.

*Author for correspondence

167
IoT market, on preliminary forecast, will grow to $\$ 7.1$ trillion in 2020 for its worldwide market [6].

The direction of IoT becomes fundamental in current technologies as how devices and smart sensors are interacting with each other. Furthermore, the emerging technology of IoT which has gained huge attention that resulted in it to be widely used in various kind of industries and environments such as security, home, healthcare, autonomous vehicle, waste management, and logistics [7, 8]. These scenarios imply that IoT is a large-scale ecosystem of socio-technical applications [9].

According to the forecast, medical devices and applications of IoT healthcare market will rise to $\$ 136$ billion in 2021 [10]. One of the most essential and attractive IoT applications is in healthcare. The IoT-driven capacity has been growing with various 
medical applications such as remote healthcare application, chronic illnesses monitoring, exercise monitoring, elderly medication, hospital discharge care, and proper drug-patient associations. Furthermore, the benefit of IoT healthcare is helping to drive down cost and time as the diagnostics and treatments are more personalized and convenient [11]. The paths to proactive medical care are opened through the continuous health monitoring system. Moreover, the connectivity of healthcare through the IoT can enhance the patient's health and experience, minimize errors, and improve the outcomes of the treatment [12]. Hospitalized patients whose physiological condition can be monitored using IoT application will bring the medical monitoring mechanism to an entirely different level. Hence, the development of IoT healthcare is challenging, to merge smart healthcare monitoring framework and smart cities, consider media processing sharing and integration with the existing healthcare systems [13]. Remote health monitoring has a three-tier architecture:

i) body sensor network that made up of medical gadgets and wearable sensors as data collection;

ii) multiple sensors connecting to a network and transferring the data;

iii) processing and analyzing the collected data to generate a report. The medical data can be accessed anywhere at any time by healthcare facilities such as hospital, clinic, medical insurance, ambulance, and the emergency team over the Internet.

In recent years, however, data protection and privacy have been one of the central and realistic challenges in the creation of IoT-based healthcare where data are required to be protected from any malicious attack that can threaten human life [14]. Data protocols and norms are lacking in IoT devices. Moreover, there is some confusion about the control of data ownership. Thus, both patients and doctors with Personal Health Information (PHI) are highly vulnerable to cyber hackers who can break into the system [14]. Some researchers proposed authentication mechanisms to protect the data within the devices. The data transmission to the centre of the cloud may lose integrity and confidentiality without data security, particularly for the data received from limited devices [15]. Regardless of the mechanisms, IoT devices have a limited resource in term of memory, processing and energy, which may cause data overload and distort the data accuracy. It is essential to understand and simulate the IoT due to the complexity to design and to manage [16]. Consequently, the accuracy, processing time and current challenges of IoT-based healthcare are studied by most researchers. This article provides a study of current IoT modelling and simulation in healthcare technology applications. The objective of this article is to highlight the IoT-based healthcare applications, specifically for blood pressure control, monitoring of the level of glucose and cholesterol, asthma monitoring, and stroke recovery method. Furthermore, some modelling and process in healthcare monitoring systems are clarified in this paper, as well as the simulation results based on the previous works. The discussion focuses on the performance and quality of health information from the patient.

\section{IoT in healthcare application}

IoT healthcare creates ways to collect, interpret and exchange data on the patient wellbeing. Without visiting the hospital or clinic, patients may monitor their health conditions. In short, more accessibility means more open data for patients and an improved health care. Based on the data collection, various health conditions can be monitored through the healthcare applications. In this section, a few existing methods and devices are briefly explained.

\subsection{Blood pressure monitoring}

Hypertension or high blood pressure is one of the chronic diseases that the risk of heart disease, stroke, and sometimes death can increase and lead to health complications. According to the World Health Organization (WHO), over a billion people worldwide have hypertension and less than 1 in 5 people with hypertension have the problem under control [17]. Thus, it is important to continuously diagnose and monitor the blood pressure to have a better understanding of cardiovascular diseases. Table 1 shows the method and device used in past studies, specifically for hypertension.

\subsection{Glucose and cholesterol level monitoring}

Diabetes is a chronic metabolic disorder that happens when blood sugar or blood glucose levels are higher in the body. Diabetes connected with high blood cholesterol that may contribute to cardiovascular diseases (stroke and heart attack). Conventionally, to measure the glucose and cholesterol level, it can be completed by taking a blood sample of the patient. Self-monitoring allows patients to measure diabetes and cholesterol levels and avoid long-term complications through the development of technology. The method and device used for monitoring the glucose and cholesterol level are presented in Table 2. 
Table 1 Method and device used for hypertension

\begin{tabular}{|c|c|c|c|}
\hline Author & Method/device & Remark & Limitation/future work \\
\hline$[18]$ & $\begin{array}{l}\text { Method: } \\
\text { Oscillometric. } \\
\text { Devices: } \\
\text { Omron M6 comfort, } \\
\text { Omron HeM-7420, } \\
\text { Withings BP-800, and } \\
\text { Polygreen KP-7670. }\end{array}$ & $\begin{array}{l}\text { Patients can self-monitor and } \\
\text { determine systolic and diastolic } \\
\text { blood pressure. }\end{array}$ & $\begin{array}{l}\text { The limitation of International } \\
\text { Protocol, the current findings of } \\
\text { other experiments in a particular } \\
\text { community should be beneficial } \\
\text { to dispute and verify. }\end{array}$ \\
\hline [19] & $\begin{array}{l}\text { Devices: } \\
\text { Keep in Contact (KIT) RFID-based blood } \\
\text { pressure meter in conjunction with Near Field } \\
\text { Communication (NFC) and cell phones. }\end{array}$ & $\begin{array}{l}\text { The devices are developed for } \\
\text { elderly people as blood pressure } \\
\text { for a home monitoring system } \\
\text { in a secure manner. }\end{array}$ & $\begin{array}{l}\text { In the future, the device can be } \\
\text { enhanced and integrated with } \\
\text { smart medical blisters to promote } \\
\text { innovative medication treatment. }\end{array}$ \\
\hline$[20]$ & $\begin{array}{l}\text { Methods: } \\
\text { Capacitance-coupled sensing method, } \\
\text { Palpatory (PPT) method to measure the } \\
\text { diastolic blood pressures, } \\
\text { Pulse transit time (PTT) method to measure } \\
\text { the systolic blood pressure. } \\
\text { Devices: } \\
\text { Finger electrocardiogram (ECG), and } \\
\text { Photoplethysmogram (PPG). }\end{array}$ & $\begin{array}{l}\text { The machines obtained signals } \\
\text { from the fingers to obtain } \\
\text { systolic and diastolic blood } \\
\text { pressure beat-to-beat with the } \\
\text { heart rate. The data } \\
\text { measurement is stored in the } \\
\text { cloud server, and then the result } \\
\text { is transmitted to mobile devices. }\end{array}$ & $\begin{array}{l}\text { The method can be enhanced in } \\
\text { term of the robustness accuracy } \\
\text { on an individual for the } \\
\text { commercialization purpose of the } \\
\text { devices. }\end{array}$ \\
\hline$[21]$ & $\begin{array}{l}\text { Method: } \\
\text { Soft capacitive pressure sensors. } \\
\text { Device: } \\
\text { Wrinkled } \mathrm{Au}(\mathrm{wAu}) \text { thin films. }\end{array}$ & $\begin{array}{l}\text { The pressure sensors can be } \\
\text { used for applications of radial } \\
\text { arterial tonometry. It provides } \\
\text { fast response times and the } \\
\text { robustness of cyclical loadings. }\end{array}$ & $\begin{array}{l}\text { Compare the capacitive pressure } \\
\text { sensors in a broader community } \\
\text { relative to the radial arterial } \\
\text { catheter. }\end{array}$ \\
\hline
\end{tabular}

Table 2 Method and device used for monitoring the glucose and cholesterol level

\begin{tabular}{|c|c|c|c|}
\hline Author & Method/device & Remark & Limitation/future work \\
\hline$[22]$ & $\begin{array}{l}\text { Method: } \\
\text { Cryptography. } \\
\text { Devices: } \\
\text { Internet-linked eHealth platform and a } \\
\text { humanoid robot to a web-centric disease } \\
\text { control centre (DMH). }\end{array}$ & $\begin{array}{l}\text { The platform was focused on } \\
\text { diabetes management in children } \\
\text { and the activities of patient } \\
\text { compliance with their care plans. }\end{array}$ & $\begin{array}{l}\text { A technical improvement can be } \\
\text { carried out to the eHealth } \\
\text { platform, particularly on the } \\
\text { concept of the physical object } \\
\text { and cognitive ability of virtual } \\
\text { object. }\end{array}$ \\
\hline [23] & $\begin{array}{l}\text { Method: } \\
\text { Run-to-Run (R2R) control. } \\
\text { Device: } \\
\text { Wearable Continuous Glucose Monitoring } \\
\text { (CGM) sensors. }\end{array}$ & $\begin{array}{l}\text { The CGM provides proactive } \\
\text { diabetes management which can } \\
\text { have an unnecessary effect on } \\
\text { patients' daily life. The device is } \\
\text { used to track glucose } \\
\text { concentration. }\end{array}$ & $\begin{array}{l}\text { A further experiment should be } \\
\text { carried out as the vast amount of } \\
\text { patient's data may affect the } \\
\text { healthcare application accuracy. }\end{array}$ \\
\hline [24] & $\begin{array}{l}\text { Methods: } \\
\text { Amperometric, and } \\
\text { Electrochemical. } \\
\text { Device: } \\
\text { Blood total cholesterol (TC) analyzer or TC } \\
\text { test strip. }\end{array}$ & $\begin{array}{l}\text { The device provides clinical } \\
\text { information on the blood } \\
\text { cholesterol level of patients. The } \\
\text { electrochemical analyzer was } \\
\text { embedded with the total } \\
\text { cholesterol test strip into a } \\
\text { mobile computing system to } \\
\text { calculate the current produced } \\
\text { by the enzymatic reaction. }\end{array}$ & $\begin{array}{l}\text { The red blood cells may affect } \\
\text { the accurate measurement of the } \\
\text { TC test trip to be compared with } \\
\text { the optical test trip. }\end{array}$ \\
\hline
\end{tabular}

\subsection{Asthma monitoring}

Breathlessness, coughing, and wheezing are the main symptoms of asthma, which may lead to an asthma attack. Asthma is a common disease among children yet can affect people of all ages. Currently, there is no cure for asthma; however, it can be controlled by doing frequent treatments. A basic hand-held system for asthma monitoring is the peak flow meter. Various method and device used to track the asthma 
Nurul Amirah Mashudi et al.

attack and assess the respiration rate and volume are shown in Table 3.

Table 3 Method and device used to track asthma

\begin{tabular}{|c|c|c|c|}
\hline Author & Method/device & Remark & Limitation/future work \\
\hline$[25]$ & $\begin{array}{l}\text { Device: } \\
\text { ADAMM Intelligent Asthma Monitoring. }\end{array}$ & $\begin{array}{l}\text { The device is used to monitor } \\
\text { pioneering symptoms, including } \\
\text { cough rate, breathing patterns, } \\
\text { heartbeat, and body } \\
\text { temperature, of asthmatic } \\
\text { attacks. The device monitoring } \\
\text { is a wearable IoT device which } \\
\text { patients can diagnose the } \\
\text { symptoms of asthma attacks } \\
\text { using mobile devices. The data } \\
\text { measured are then transferred to } \\
\text { the cloud server, and the result } \\
\text { can be shared with the medical } \\
\text { staff. }\end{array}$ & $\begin{array}{l}\text { ADAMM is commonly used to } \\
\text { track adolescent asthma. } \\
\text { However, the cough rate among } \\
\text { teenagers has shown a low } \\
\text { asthma detection accuracy based } \\
\text { on the audio. }\end{array}$ \\
\hline [26] & $\begin{array}{l}\text { Device: } \\
\text { Wearable strain sensors. }\end{array}$ & $\begin{array}{l}\text { The device is used to assess } \\
\text { respiration rate and volume } \\
\text { with high accuracy provides } \\
\text { continuous monitoring of } \\
\text { drastic changes in breathing } \\
\text { patterns for asthma patients, } \\
\text { enabling therapy to be managed } \\
\text { promptly. }\end{array}$ & $\begin{array}{l}\text { The device was tested on a small } \\
\text { community which is not } \\
\text { sufficient to achieve a high } \\
\text { accuracy rate of the device. } \\
\text { The experiment was carried out } \\
\text { when the subject is motionless; } \\
\text { thus, further analysis must be } \\
\text { carried out for multiple types of } \\
\text { motion artefacts. }\end{array}$ \\
\hline [27] & $\begin{array}{l}\text { Methods: } \\
\text { Adaptive filtering, and } \\
\text { NLMS. } \\
\text { Devices: } \\
\text { Wearable sensor system; wristband and chest } \\
\text { patch. }\end{array}$ & $\begin{array}{l}\text { To understand the impact of } \\
\text { ozone on chronic asthma } \\
\text { conditions, the device is used to } \\
\text { allow the connection of } \\
\text { individual environmental } \\
\text { exposure to health response. } \\
\text { The battery life of the wristband } \\
\text { is around } 15 \text { hours, and the } \\
\text { chest patch is around } 36 \text { hours. }\end{array}$ & $\begin{array}{l}\text { The wristband and chest patch } \\
\text { required high power consumption } \\
\text { to optimize sensors. Further work } \\
\text { can be carried out to develop a } \\
\text { self-powered system to avoid any } \\
\text { reduction of battery life. }\end{array}$ \\
\hline
\end{tabular}

\subsection{Stroke rehabilitation system}

According to World Health Organization (WHO), the second leading cause of death worldwide is stroke. In 2016, there are around 56.9 million death globally, accounting for 5.9 million deaths due to stroke [28]. Upper limb function received great attention for stroke survivors as it is slower and has difficult recovery [29], to be compared with lower limb function. Rehabilitation training is important for the upper limb function. The process and device used to develop the recovery system for stroke patients are presented in Table 4.

Table 4 Method and device used to track asthma

\begin{tabular}{llll}
\hline Author & Method/device & Remark & Limitation/future work \\
\hline$[30]$ & Method: & The method and device have & The shortage of medical \\
& RehabMaster. & prove to be a safe resources leads to a lack of \\
& Device: & rehabilitation method for clinical advice, and the \\
& Virtual Reality (VR) system. & amproving motor function physiotherapist unable to track \\
& phases of post-stroke recovery. their recovery. \\
& Hospitals and physiotherapist \\
& will be high demand for the \\
& medical resource of for elderly \\
& people.
\end{tabular}




\begin{tabular}{|c|c|c|c|}
\hline Author & Method/device & Remark & Limitation/future work \\
\hline [31] & $\begin{array}{l}\text { Methods: } \\
\text { Hand gesture } \\
\text { Recognition, } \\
\text { Support Vector Machine (SVM), and } \\
\text { K-Nearest Neighbors. }\end{array}$ & $\begin{array}{l}\text { The purpose of this study is to } \\
\text { monitor post-stroke patient } \\
\text { recovery movements. }\end{array}$ & $\begin{array}{l}\text { Further work can be achieved in } \\
\text { developing the device to share } \\
\text { the result of the patient's hand } \\
\text { movement to the physiotherapist. }\end{array}$ \\
\hline$[32]$ & $\begin{array}{l}\text { Methods: } \\
\text { Surface electromyography (sEMG), and } \\
\text { Machine learning. } \\
\text { Devices: } \\
\text { Smart wearable armband, and } \\
\text { 3D printed dexterous robot hand. }\end{array}$ & $\begin{array}{l}\text { IoT-enabled } r \text { stroke } \\
\text { rehabilitation device was } \\
\text { developed for hand } \\
\text { rehabilitation training purposes. } \\
\text { The dexterous robot hand will } \\
\text { imitate the movements of the } \\
\text { patient in a real-time mode. }\end{array}$ & $\begin{array}{l}\text { The device was performed to the } \\
\text { same subject. A variety of user- } \\
\text { condition should be conducted to } \\
\text { obtain the reliability of the } \\
\text { device, particularly for stroke } \\
\text { patients. }\end{array}$ \\
\hline
\end{tabular}

\section{Modelling of healthcare application}

The modelling of IoT healthcare applications will be explained in detail in this section for blood pressure monitoring and stroke rehabilitation system. The methods and devices for both blood pressure monitoring and stroke rehabilitation system were briefly described in Section 2.

\subsection{Blood pressure monitoring}

Measurements of blood pressure using finger ECG and PPG [20] have been suggested by researchers using a capacitance-coupled ECG sensing system due to the discomfort of using conductive gel or patch ECG sensors. The blood pressure with heart rate is measured using a mall device of PPT system. Furthermore, a new type of sensors has been used to sense the ECG and PPG on fingertips. Blood pressure readings are then transmitted to mobile devices or the Internet. The data is maintained for monitoring purposes on a cloud server. Main hardware components used are explained as below:

i) Rechargeable power supply

A rechargeable power supply is used to run the analogue circuit using electrical potential integrated circuit sensors while the light sensor is used to obtain the PPG waveform, and ECG is detected at the fingertips.

\section{ii) Microcontroller}

To digitize and process the signals, a 10-bit ADC built-in is used. Wireless module received the estimated heart rate, systolic and diastolic blood pressure. Two equations for systolic blood pressure (SBP) and diastolic blood pressure (DBP) implemented in the microcontroller are:

$S B P=4.8008600358 \times 10-4 \times P T T+1.308532932$

$D B P=-6.23533972 \times 10-4 \times P P T+1.37708918$

iii. Wireless module
The prototype of ECG and PPG contained in a mobile device case is shown in Figure 1. The ECG has two sensors, and required both two thumbs of patients. The simple flow chart of the modelling of ECG PPG blood pressure application is illustrated in Figure 2.

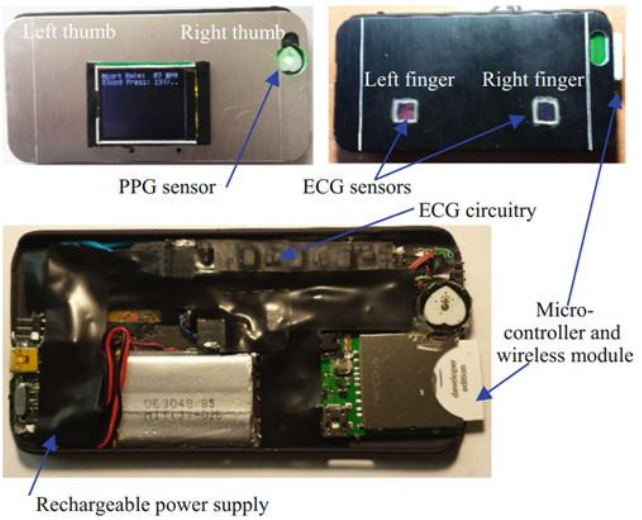

Figure 1 Prototype of the designed that contained in a mobile device case

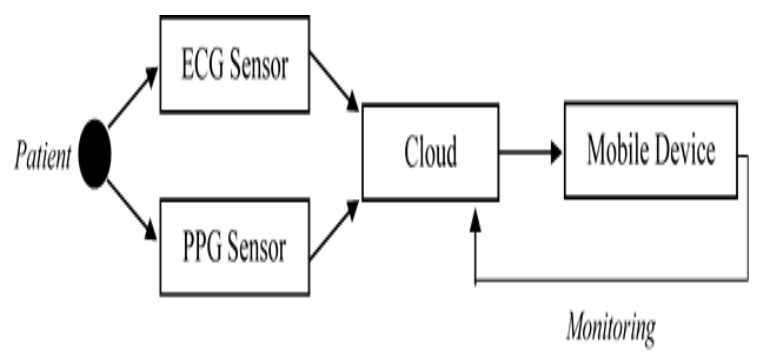

Figure 2 Flow of modelling of ECG PPG blood pressure application

\subsection{Stroke rehabilitation system}

For the hand recognition stroke rehabilitation IoT system, integration of machine learning, smart wearable armband device, and 3D printed robot hand was developed by [32]. There are two main components of the prototype: the smart wearable 
armband (SWA) and the smart training equipment (STE).

i) Smart wearable armband

The purpose of the smart wearable armband is to record, pre-process, and transmit the surface electromyography (sEMG) signals to the STE via wireless communication. High pass filters, analogue front-end, wireless module and textile electrodes compose the SWA. Comfort and softness are the main highlights of the SWA design, while the fabrication employed textile electrodes and stretchable material, as shown in Figure 3.

ii) Smart training equipment

STE consists of a Machine Learning algorithm and a robot hand-printed in 3D. The Machine Learning (ML) algorithm-based real-time gesture recognition was mapped to monitor the 3D printed robot hand, as shown in Figure 4.

The robot hand was developed using 3D printing technology and, due to its low cost, fast and opensource platform, the Arduino Mega 2560 was chosen as an electronic control unit. Consecutively, the thumb-related servo motor retained its original angle to comprehend the motion of the five-finger dexterous robot hand. The remaining four servo motors meanwhile, drove the corresponding reels to rotate, bending the remaining four 3D printed fingers further.

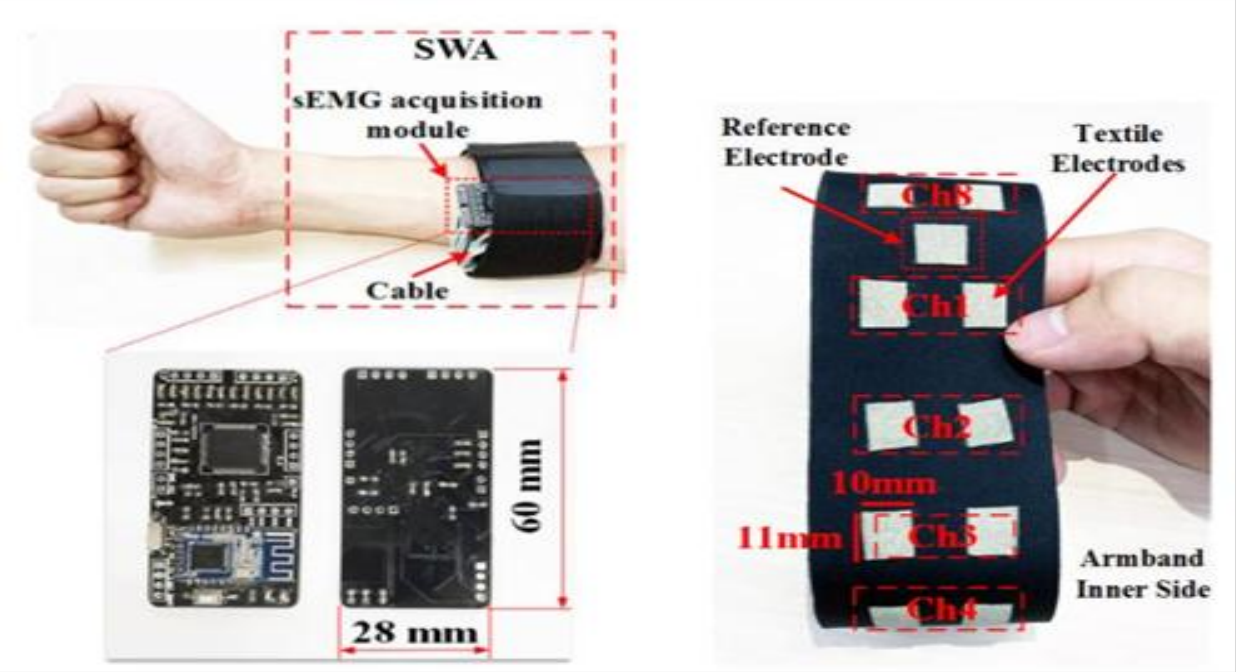

Figure 3 Smart wearable armband

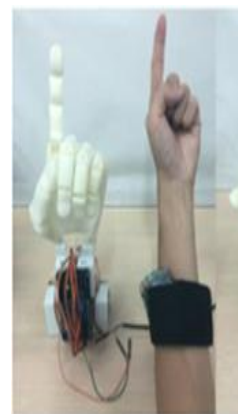

a)

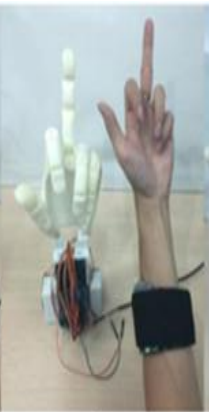

b)

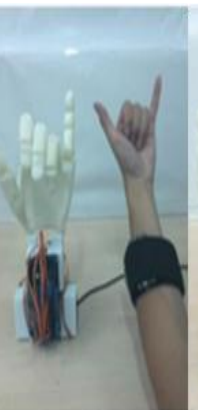

c)

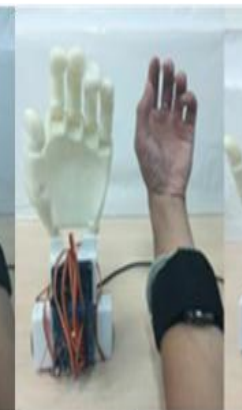

d)

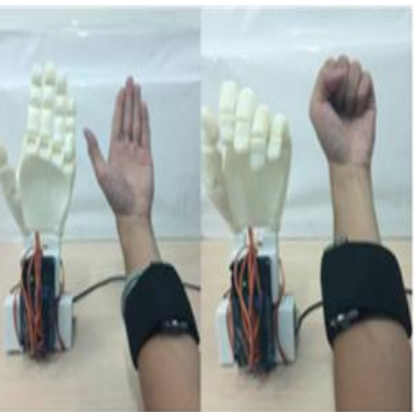

e)

f)

Figure 4 Real-time gesture recognition to guide a dexterous robot with five fingers

\section{Simulation process}

Simulation is the imitation operation of a model of a real-world process or system over time. It is also a transition from a mathematical or computer model to a description of the system behaviour based on sets of input parameters. Simulation describes the system operation over time. This section describes the simulation of a selected blood pressure control and stroke recovery device, as described in Section 3. 


\subsection{Blood pressure monitoring}

The flow of the blood pressure monitoring system is presented in Figure 5. Portapres has been used to continuously measure the blood pressure and compare with the results gained. Patients put two fingers on the ECG sensors, and the thumbs are then placed on the case of the mobile device and on the top of the PPG light sensor. The data collected consisted of the heart rate, ECG, Portapres waveform, PPG waveform, systolic and diastolic blood pressure to assess the coefficient for estimating blood pressure, as shown in Figure 6. Moreover, to determine the relationship between PTT and blood pressure, this information was analyzed. Data from two waveforms is used to calculate blood pressure using the PTT procedure. All the R peaks were located using the ECG waveform. It calculated the PPG's top, centre and foot and measured the PPT.

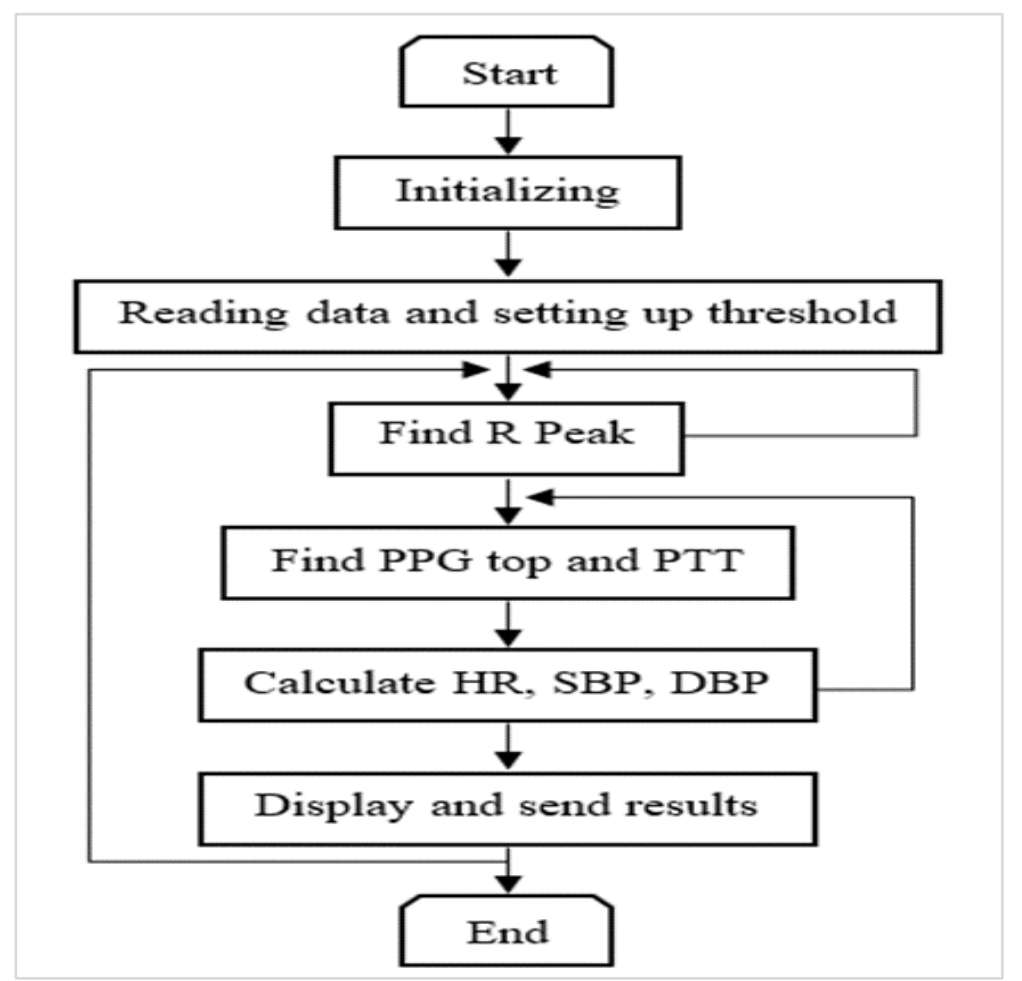

Figure 5 Blood pressure monitoring system flow

\subsection{Stroke rehabilitation system}

SWA and STE are the main devices in receiving data from after stroke patients. The first SWA approach is that a $10 \mathrm{~Hz}$ high pass philtre circuit will filter each channel's raw sEMG signal that can elude the saturation of the amplifier caused by the motion product. The signal was then amplified and digitized by ADS1198; a TI low-power analogue front-end with eight channels. This analogue front-end consists of built-in programmable gain amplifiers, 16-bit analogue-to-digital converters, and an integrated right-leg drive amplifier designed to limit the noise mode of the electric muscle signal. Finally, the preprocessed sEMG upper extremity signal was transmitted to STE in the packet structure via a wireless module. The wireless communication has been achieved using TI transceiver CC2540.

The first phase of the wireless module receiving preprocessed sEMG signals from SWA and transmitting them to the PC host is then performed by STE once SWA has been completed. All nine motions can be successfully recognized. The target motion collection includes Accept, close hand, open hand, pointer, thumb and middle finger, thumb and small finger, flex hand, extended hand and relax. The overall framework for SWA and STE is illustrated in Figure 7. 
Nurul Amirah Mashudi et al.

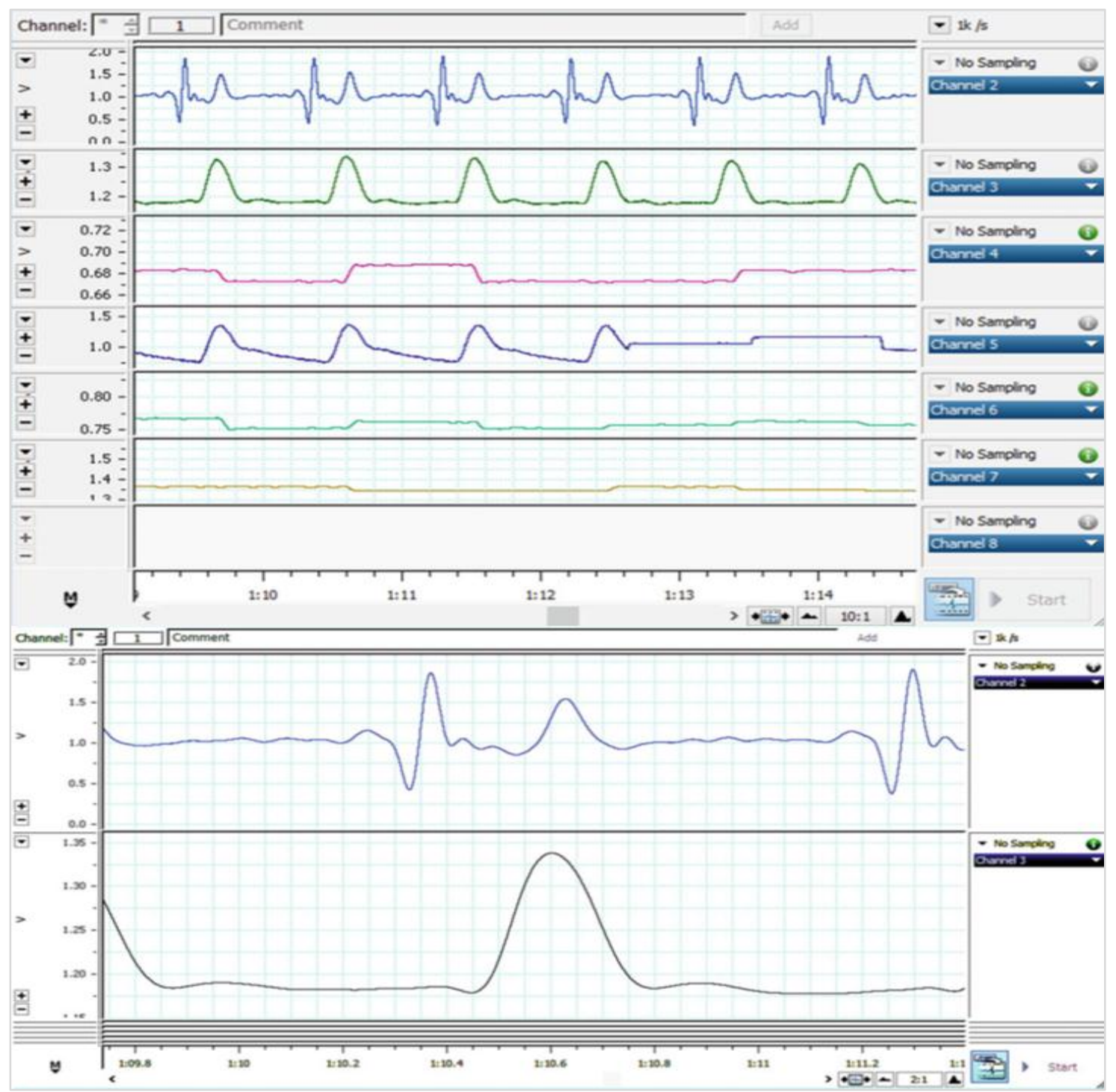

Figure 6 Coefficients for blood pressure estimation waveform

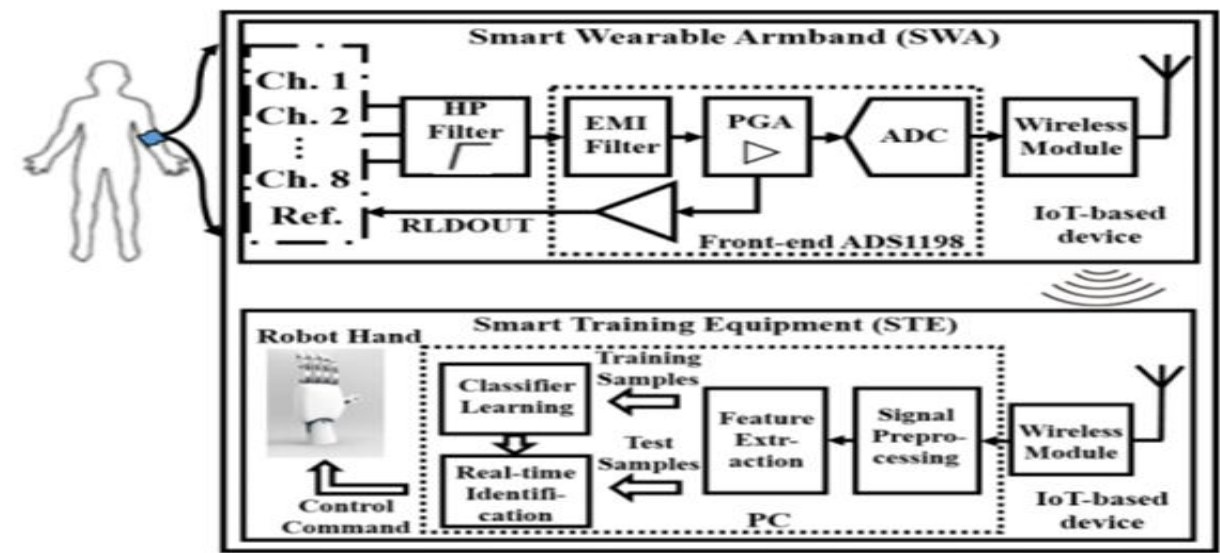

Figure 7 SWA and STE framework 


\section{Outlook}

The challenge of the IoT in the healthcare industry will have to be resolved, specifically on the usability, accuracy and security of devices. Most researchers have performed the device testing to a minor community instead of the real-patient who has the disease. Thus, the accuracy would be limited to the individual, and to bring the device for a commercialize purpose would be challenging. A variety of user condition is necessary to achieve a robust performance of the devices. On the technical side of view, the IoT needs to be specified in order to enable a further wider acceptance to the people.

\section{Conclusion}

The modelling and simulation of the IoT in healthcare application has been presented. Smart healthcare application is one of the essential IoT applications in smart cities. Various healthcare application has been developed and proposed to reach the new advancements of technologies. The IoTbased healthcare applications presented in this paper comprise of glucose and cholesterol level monitoring, blood pressure monitoring, asthma monitoring, and stroke rehabilitation system. The modelling and simulation of blood pressure monitoring and stroke rehabilitation system were selected to be presented in detail. The development of ECG and PPG in blood pressure measurement has made a convenience tool for patients to monitor their blood pressure at home without visiting hospital or clinic. According to the result, the integration with the smartphone has created simplicity and usability of the design for the device. However, further investigation is required for accurate blood pressure measurement. The method can also be enhanced in term of the robustness accuracy on an individual for the commercialization purpose of the devices. On the other hand, the advancement of the smart wearable armband and 3D printed robot hand for stroke rehabilitation system did good training for after stroke patients. The realtime assistance from the robot hands helps stroke patients to strengthen the muscles with their motion patterns after stroke. The result has shown that the smart wearable armband offers a convenient, subtle and easy to use without physicians needing any technical knowledge or support. Moreover, the classification accuracy was high due to the feature selection used. Thus, the performance of both blood pressure monitoring and stroke rehabilitation system has shown a better outcome of the development and product to achieve the accurate patient's health information. The future work can be carried out for a variety of user-condition to obtain and achieve the 175 reliability of the device, particularly for stroke patients.

\section{Acknowledgment}

This work is supported by Universiti Teknologi Malaysia under research University Grant Q.K130000.3556.06G45 for the financial support provided throughout this research project.

\section{Conflicts of interest}

The authors have no conflicts of interest to declare.

\section{References}

[1] Evans D. The internet of things: how the next evolution of the internet is changing everything. CISCO White Paper. 2011; 1(2011):1-11.

[2] Vestberg H. Ceo to shareholders: 50 billion connections 2020. Ericsson. 2010.

[3] Camhi J. Former cisco CEO john chambers predicts 500 billion connected devices by 2025. Business Insider. 2015.

[4] Gubbi J, Buyya R, Marusic S, Palaniswami M. Internet of things (IoT): a vision, architectural elements, and future directions. Future Generation Computer Systems. 2013; 29(7):1645-60.

[5] Vashi S, Ram J, Modi J, Verma S, Prakash C. Internet of things (IoT): a vision, architectural elements, and security issues. In international conference on ISMAC (IoT in social, mobile, analytics and cloud) 2017 (pp. 492-6). IEEE.

[6] Lund D, Macgillivray C, Turner V, Morales M. Worldwide and regional internet of things (IoT) 20142020 forecast: a virtuous circle of proven value and demand. International Data Corporation (IDC), Tech. Rep. 2014.

[7] Azzawi MA, Hassan R, Bakar KA. A review on internet of things (IoT) in healthcare. International Journal of Applied Engineering Research. 2016; 11(20):10216-21.

[8] Li S, Da Xu L, Zhao S. The internet of things: a survey. Information Systems Frontiers. 2015; 17(2):243-59.

[9] Savaglio C, Fortino G, Zhou M. Towards interoperable, cognitive and autonomic IoT systems: an agent-based approach. In 3rd world forum on internet of things (WF-IoT) 2016 (pp. 58-63). IEEE.

[10] Malik MA. Internet of Things (IoT) Healthcare market by component (implantable sensor devices, wearable sensor devices, system and software), application (patient monitoring, clinical operation and workflow optimization, clinical imaging, fitness and wellness measurement): global opportunity analysis and industry forecast, 2014-2021. Allied Market Research. 2016.

[11] Lee K, Gelogo YE, Lee S. Mobile gateway system for ubiquitous system and internet of things application. International Journal of Smart Home. 2014; 8(5):27986. 
[12] Islam SR, Kwak D, Kabir MH, Hossain M, Kwak KS. The internet of things for health care: a comprehensive survey. IEEE Access. 2015; 3:678-708.

[13] Hossain MS, Muhammad G, Alamri A. Smart healthcare monitoring: a voice pathology detection paradigm for smart cities. Multimedia Systems. 2019; 25:565-75.

[14] Zhang X, Liu S, Chen X, Wang L, Gao B, Zhu Q. Health information privacy concerns, antecedents, and information disclosure intention in online health communities. Information \& Management. 2018; 55(4):482-93

[15] Selvaraj S, Sundaravaradhan S. Challenges and opportunities in IoT healthcare systems: a systematic review. SN Applied Sciences. 2020; 2:1-8.

[16] D'angelo G, Ferretti S, Ghini V. Simulation of the internet of things. In international conference on high performance computing \& simulation (HPCS) 2016 (pp. 1-8). IEEE.

[17] Noncommunicable diseases country profiles 2018. World Health Organization. Geneva. 2018.

[18] Topouchian J, Agnoletti D, Blacher J, Youssef A, Chahine MN, Ibanez I, et al. Validation of four devices: omron m6 comfort, omron HEM-7420, withings BP-800, and polygreen KP-7670 for home blood pressure measurement according to the European society of hypertension international protocol. Vascular Health and Risk Management. 2014; 2014(10):33-44.

[19] Dohr A, Modre-Opsrian R, Drobics M, Hayn D, Schreier G. The internet of things for ambient assisted living. In seventh international conference on information technology: new generations 2010 (pp. 804-9). IEEE.

[20] Dinh A, Luu L, Cao T. Blood pressure measurement using finger ECG and photoplethysmogram for IoT. In international conference on the development of biomedical engineering in Vietnam 2017 (pp. 83-9). Springer, Singapore.

[21] Kim J, Chou EF, Le J, Wong S, Chu M, Khine M. Soft wearable pressure sensors for beat-to-beat blood pressure monitoring. Advanced Healthcare Materials. 2019; 8(13).

[22] Al-Taee MA, Al-Nuaimy W, Muhsin ZJ, Al-Ataby A. Robot assistant in management of diabetes in children based on the internet of things. IEEE Internet of Things Journal. 2016; 4(2):437-45.

[23] Cappon G, Acciaroli G, Vettoretti M, Facchinetti A, Sparacino G. Wearable continuous glucose monitoring sensors: a revolution in diabetes treatment. Electronics. 2017; 6(3):1-16.

[24] Fu Y, Guo J. Blood cholesterol monitoring with smartphone as miniaturized electrochemical analyzer for cardiovascular disease prevention. IEEE Transactions on Biomedical Circuits and Systems. 2018; 12(4):784-90.

[25] Kang M, Park E, Cho BH, Lee KS. Recent patient health monitoring platforms incorporating internet of things-enabled smart devices. International Neurourology Journal. 2018; 22(Suppl 2):S76-82.
[26] Chu M, Nguyen T, Pandey V, Zhou Y, Pham HN Bar-Yoseph $\mathrm{R}$, et al. Respiration rate and volume measurements using wearable strain sensors. NPJ Digital Medicine. 2019; 2(1):1-9.

[27] Dieffenderfer JP, Goodell H, Bent B, Beppler E, Jayakumar R, Yokus M, et al. Wearable wireless sensors for chronic respiratory disease monitoring. In 12th international conference on wearable and implantable body sensor networks (BSN) 2015 (pp. 16). IEEE.

[28] The top 10 causes of death-homepage. Genebra: World Health Organization. 2019.

[29] Nichols-Larsen DS, Clark PC, Zeringue A, Greenspan A, Blanton S. Factors influencing stroke survivors' quality of life during subacute recovery. Stroke. 2005; 36(7):1480-4.

[30] Shin JH, Ryu H, Jang SH. A task-specific interactive game-based virtual reality rehabilitation system for patients with stroke: a usability test and two clinical experiments. Journal of Neuroengineering and Rehabilitation. 2014; 11:1-10.

[31] Li WJ, Hsieh CY, Lin LF, Chu WC. Hand gesture recognition for post-stroke rehabilitation using leap motion. In international conference on applied system innovation 2017 (pp. 386-8). IEEE.

[32] Yang G, Deng J, Pang G, Zhang H, Li J, Deng B, et al. An IoT-enabled stroke rehabilitation system based on smart wearable armband and machine learning. IEEE Journal of Translational Engineering in Health and Medicine. 2018; 6:1-10.

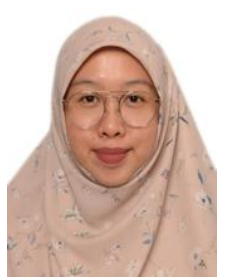

Nurul Amirah Mashudi received a Bachelor of Computer Science (Graphics and Multimedia Software) in 2016 from Universiti Teknologi Malaysia, Johor Bahru. Currently, she is pursuing her Master's Degree in Science (Systems Engineering) at Universiti Teknologi Malaysia, Kuala Lumpur. Her current research areas are Image Processing, Image Analysis, Machine Learning, and Deep Learning. Email: amirahmashudi@gmail.com

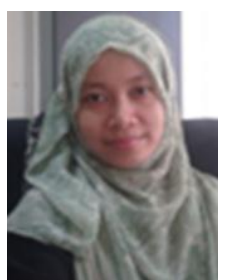

Hazilah Mad Kaidi is a senior lecturer in Razak Faculty of Technology and Informatics. She received her M.Sc. degree in Telecommunication and Information Engineering at Universiti Teknologi MARA Malaysia, the B.Eng (Horns) in Electrical Engineering in Telecommunication and the $\mathrm{PhD}$ degree from the Universiti Teknologi Malaysia. Her research interests include mobile and Wireless Communications, Error Control Coding, Relay Networks, Cooperative Communications, Hybrid ARQ, Cross-Layer Design, Internet of Things, and Green Technology. Email: hazilah.kl@utm.my 


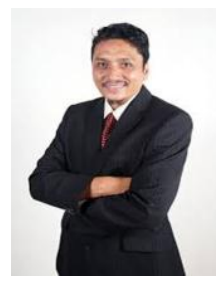

Shamsul Sarip is an academic staff of Razak Faculty of Technology and Informatics, Universiti Teknologi Malaysia Kuala Lumpur. He received Diploma of Mechanical Engineering in 1995, Bachelor of Mechanical Engineering in 1998, and Master of Mechanical Engineering in 2002 from the Universiti Teknologi Malaysia. He then obtained his $\mathrm{PhD}$ in Mechanical Engineering from the University of Bradford, the United Kingdom in 2012. He involved in university motorsport activities which required him to expand the knowledge to Finite Element Analysis, Heat Transfer, Computational Fluid Dynamics and Structure Analysis.

Email: shamsuls.kl@utm.my

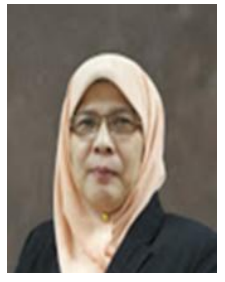

Liza Abdul Latiff is an Associate Professor in Razak Faculty of Technology and Informatics. She obtained her B. Sc in Electrical Engineering from South Dakota State University, USA (1985), Masters in Electrical Engineering (Data Communication) from UTM (1988) and $\mathrm{PhD}$ in Electrical Engineering in 2007 from UTM also. Her research interests are computer networking in both Wireless and Wired Communication, Routing Protocols, Scheduling and Mobility Management and IoT in Healthcare Industry.

Email: liza.kl@utm.my 